\title{
Adult children of parents with young-onset dementia narrate the experiences of their youth through metaphors
}

This article was published in the following Dove Press journal:

Journal of Multidisciplinary Healthcare

27 May 2015

Number of times this article has been viewed

\author{
Aud Johannessen' \\ Knut Engedal' \\ Kirsten Thorsen ${ }^{1,2}$ \\ 'Vestfold Hospital Trust, Norwegian \\ National Advisory Unit on Ageing and \\ Health, Tønsberg, ${ }^{2}$ University College \\ of Oslo and Akershus, Oslo, Norway
}

Correspondence: Aud Johannessen Vestfold Hospital Trust, Norwegian National Advisory Unit on Ageing and Health, PO Box 2136 NO-3I03,

Tønsberg, Norway

Tel +47975 47979

Email aud.johannessen@aldringoghelse.no
Background: Limited research exists on the development and needs of children of parents with young-onset dementia (YOD) ( $<65$ years old). There is scarce knowledge of how these children experience the situation of growing up with a parent with dementia. This study investigates the stories of children of persons with YOD and interprets their metaphorical expressions of their experiences as a source of understanding their situation and needs during the development and course of their parent's dementia.

Methods: Qualitative interviews with 14 informants (aged 18-30 years; nine daughters, five sons) were conducted in 2014 and subsequently analyzed by the informants' use of metaphors. Steger's three-step method for analyzing metaphors was applied.

Results: The analysis identified four themes in the metaphors: the informants' relations to the disease, to the self, to the parent, and to others. From these themes, four core metaphors were abstracted: "my parent is sliding away"; "emotional chaos"; "becoming a parent to my parent"; and "a battle".

Conclusion: The study revealed that growing up with a parent with dementia has a great impact on the children's situation and their experiences of their personal development. Children of a parent with YOD are a group with unmet needs for support. A formalized system where the children can get into contact with service providers to receive tailored information and individual follow-up needs to be established. The service providers must listen to the children's stories, perceive how metaphors convey their experiences, and recognize their need for support for their own development.

Keywords: adult children, early-onset dementia, experiences, metaphors, services, support

\section{Introduction}

The dementia syndrome diagnosed in persons under the age of 65 years is often referred to as "young-onset dementia" (YOD). Based on the prevalence study of Harvey et al, ${ }^{1}$ it has been estimated that up to 1,400 Norwegian citizens are diagnosed with dementia before the age of 65 years. With more knowledge and better diagnostic tools, we believe that today, the real prevalence of dementia in persons aged 64 years and younger is at least $3,000 .^{2}$ Still, the group of people with YOD is relatively small compared to the 70,000 people in Norway who develop dementia above the age of 65 years. ${ }^{3}$

Some important differences between dementia that develops before and after the age of 65 years can lead to a higher burden among family caregivers. At first, behavioral and psychological symptoms of dementia and the occurrence of frontotemporal dementia in the age group younger than 65 years are more frequent than in the older population with dementia. ${ }^{4}$ Second, since people with YOD are middle-aged, the 
disease will concern many family members in different ways when compared to the families of older people with dementia. Among the people involved are the close family, the spouse, and children; in many cases, parents and siblings are also involved. Review studies on YOD have shown that the families of persons with YOD need special social and emotional support tailored to their situation - caring for a middle-aged person - during the development and course of the dementia disorder. ${ }^{5,6}$

We do not know exactly how many of the persons with YOD have children when the disease starts, but according to earlier Norwegian data, ${ }^{7}$ we assume that at least onethird of them have children younger than 18 years with the onset of the dementia disorder. Most dementia disorders develop gradually, and the family might encounter increasing challenges. Persons with young-onset Alzheimer's disease $(\mathrm{AD})$ have difficulties remembering appointments and messages, and foresight and planning in the family is disturbed. The family members become worried, confused, and fearful when important information is forgotten. ${ }^{8-12}$ The children may experience guilt and shame, and feel embarrassed when their friends meet their parent who is forgetful (AD) or exhibits a change in personality (frontotemporal dementia, especially). ${ }^{8} 9$ It might be difficult to live a normal adolescent life and perform at the same level in school and at work as before when living with a parent with dementia. Most children need a follow-up when the parent receives a dementia diagnosis. Some experience conflicts with the parent with dementia, and this is particularly the case for children of patients with behavior disturbances. ${ }^{9,11}$ Studies show that, with a few exceptions, no structured services for children of persons with YOD are provided. ${ }^{5,13}$ Furthermore, it is important that children of parents with YOD are given possibilities to express their thoughts, feelings, and perceptions of their present needs and situations, and how their own development has been affected during the time period that the parent has had symptoms of dementia., ${ }^{911-15}$

The main task of youth is to develop a robust sense of self, identity, self-respect, and self-confidence - to become a vital actor in one's own life. ${ }^{16,17}$ In this process, the parents are mirrors for their children, ${ }^{18-20}$ being affirmative and directing, and serving as models for their children. Having a parent with dementia during youth in many ways deviates from what is considered a normal parent-child relationship. ${ }^{21,22}$

One way of expressing thoughts, feelings, and perceptions is through metaphors as a source of information. Metaphors are words or figures of speech, displacing or extending the meaning of words by substituting one word with another. ${ }^{23}$
Metaphors have been described as a "lens", ${ }^{24}$ providing us with special insights and data about the narrator and his or her emotions, beliefs, and self-concepts, which are often unconsciously produced. ${ }^{25}$ Metaphors have been used about illnesses ${ }^{26}$ and are fundamental to patients in perceiving, interpreting, and defining symptoms and motivating them to seek care. ${ }^{27}$ Also, metaphors in the stories of experiences of people with YOD have been described and analyzed. ${ }^{28}$

With this background, we have carried out the present study to investigate and interpret the metaphorical expressions of the experiences of children of persons with YOD, which represent a way in which to understand their situation and needs during the development and course of their parents' dementia. The research question in the present study was thus formulated: How do adult children of persons with YOD describe their experiences in everyday life with metaphors, and how might these metaphors be understood?

\section{Methods}

The basic design of this study involves a qualitative phenomenological hermeneutic approach, which was used to analyze the informants' use of metaphors in narratives. This method has the advantage of exploring the subjective life world of the informants and the ways that the persons experience, give meaning to, and narrate their feelings and cognitions. ${ }^{29}$ A narrative approach is described by Mishler ${ }^{30}$ as an approach that elicits stories or events. We use the metaphorical analysis of narratives of adult children to persons with YOD to gain insight into their experiences of having a parent with dementia.

Montagne $^{27}$ defines metaphors as poetically formulated bits of language that imply a relationship of similarity between two things, and so they change our apprehension of either or both. Lakoff and Johnson's ${ }^{31}$ cognitive-semantic theory of metaphorical concepts underlines that metaphors are not a mere ornamental linguistic style; rather, they potentially affect our conception of reality. This conception then guides our cognition and actions. Metaphors convey meanings, ${ }^{32}$ but emotions and associations are also connected to the metaphorical ways of describing things. Metaphors are conventions - cultural and stereotypical ways of describing things and events - but they are rooted individually. ${ }^{31}$

Lakoff and Johnson ${ }^{31}$ claim that our way of thinking is predominantly metaphorical, structured, and defined, and not just a way of talking. They introduced a four-fold typology of metaphors: structural, orienting, ontological, and new metaphors. Each of these contributes in different ways 
to explain and give meaning to aspects of individual and cultural processes.

Steger ${ }^{25}$ describes the wealth and breadth of the types of metaphors and the stories the metaphors tell. He emphasizes that metaphors can be created consciously and unconsciously, have a cognitive as well as an affective component, be of simple and complex form, be concrete or abstract, be figures of speech as well as figures of thought, be models for a description of systems and situations (models of the situation) and "root-metaphors", function as action generators (models for the situations), and be "real labels" or platitudes of the time. ${ }^{25}$ Furthermore, metaphors can reduce complexity or introduce complexity, communicate the inexpressible, describe self-concepts and emotions, and contribute to narratives about experiences. ${ }^{25}$

\section{Participants}

We wanted to explore variations in experiences and life situations. To attain heterogeneity, we included persons from different areas in the southern and western parts of Norway. Two memory clinics, one municipality, a nursing home designed to provide care for persons with YOD, and the Norwegian National Support Group for Adult Children of people with YOD were asked to recruit participants. We included adult children of persons with YOD in various types and stages of dementia disorders.

The study took place in 2014. A total of 16 adult children, 18 years or older, were asked to participate; two declined. Thus, the sample consisted of 14 informants, from
18-30 years old (mean: 24 years). The first signs of dementia were difficult to place in time, but the children remembered that dementia in their parents started six months to 13 years before the diagnosis was made. The diagnosis was made in the time period from 6 months to 10 years before the interview took place. Other characteristics of the participants are described in Table 1.

\section{Data collection}

The data were collected through individual qualitative interviews and were performed at the most appropriate place for the informants. ${ }^{33-35}$ Ten of the interviews took place at the informants' homes, three at the interviewer's workplace, and two interviews took place at the informant's workplace. The interviews were based on an interview guide with six open-ended thematic questions focusing on the informants' experiences of having a parent with YOD. The questions are listed in Table 2.

Depending on their replies, the aspects and ideas raised by the informants led to further questions in order to obtain additional information. Some specific information, covering biographical and demographic information about the parent and child, the diagnosis, and the progression of dementia, as well as responses to questions about specific services were also collected. The interviews were carried out by the author (AJ), lasted for 15-51 minutes (mean: 39 minutes), and were tape recorded. The recorded interviews were transcribed verbatim by a professional typist within 2 weeks after each interview. A quality control check of the transcripts was

Table I Characteristics of the adult children and their parent with YOD

\begin{tabular}{|c|c|c|c|c|}
\hline \multicolumn{3}{|c|}{ The adult child } & \multicolumn{2}{|c|}{ The parent with YOD } \\
\hline Relationship & Siblings & Household & Relationship & Household \\
\hline Daughter & Two half siblings ${ }^{a}$ & Living at parental home ${ }^{b}$ & Father & Married \\
\hline Daughter & Two siblings & Living alone $\mathrm{e}^{\mathrm{b}, \mathrm{c}}$ & Mother & Widow \\
\hline Daughter & Five siblings & Living alone $\mathrm{e}^{\mathrm{b}, \mathrm{c}}$ & Mother & Divorced \\
\hline Daughter & Two siblings & Cohabitation $^{c}$ & Mother & Widow \\
\hline Daughter & Two siblings & Married ${ }^{c}$ & Mother & Married \\
\hline Daughter & None & Cohabitation $^{\mathrm{b}}$ & Mother & Divorced \\
\hline Daughter & One sibling & Cohabitation $^{c}$ & Father & Married \\
\hline Daughter & One sibling & Married $^{c}$ & Father & Divorced \\
\hline Daughter & One sibling & Cohabitation ${ }^{b, c}$ & Father & Married \\
\hline Son & Three siblings ${ }^{\mathrm{a}}$ & Living at parental home ${ }^{b}$ & Father & Married \\
\hline Son & One sibling & Living with his mother & Father & Divorced \\
\hline Son & Three siblings ${ }^{a}$ & Living with his sister ${ }^{\mathrm{b}}$ & Father & Married \\
\hline Son & $\begin{array}{l}\text { One sibling, two } \\
\text { half siblings }^{\mathrm{a}}\end{array}$ & Cohabitation & Father & Married $^{d}$ \\
\hline Son & None & Living alone $\mathrm{b}^{\mathrm{b}}$ & Father & Married \\
\hline
\end{tabular}

Notes: aDo not live together in the same household; blived together with the parent when the first signs of dementia were revealed or the diagnosis was made; chave their own children; ${ }^{d}$ the parent is married again.

Abbreviation: YOD, young-onset dementia. 
Table 2 Questions/themes in the interviews of the adult children of a parent with YOD

- How was it during those years and how is it now for you to have a parent with YOD?

- How has this disease affected your life in the different stages of the disorder?

- How has the disorder affected your family and the relationships within the family, and among your friends in the different stages of the disorder?

- When you look back, is it possible for you to describe something that has been/could have been of help to you or your family during the different stages of the disorder?

- What kind of support have you received, do you receive, or you are in need of today?

- Have you had to make decisions for your parent with YOD, and if so, how has that been?

Abbreviation: YOD, young-onset dementia.

performed by the interviewer listening to the tapes while AJ read the interviews.

\section{Analysis}

In the present study, the experiences of the children of a person with YOD are described through an analysis of metaphors using the theoretical understanding of Stegers ${ }^{25}$ three-step metaphor analysis. In line with Stegers, ${ }^{25}$ we pursued an individual perspective, taking into consideration the meaning of the metaphor in its special context.

The first step of the analysis ${ }^{25}$ is metaphor identification and selection. We did, as Steger recommends, a "parallel reading". Two of the researchers (AJ and KT) individually read the text several times to gain an overview, and each marked relevant metaphors. We looked for repetition, elaboration, relatedness, contrast, and emotion, as suggested by Steger. ${ }^{25}$ Most of the metaphors were marked by both: the metaphors characterizing the experiences of their parent's dementia; the informant's own feelings and experiences; and their relationship to their parents. These metaphors were ontological metaphors ${ }^{31}$ used by the individuals to describe and understand their own experiences of relevance for their ways of handling the situation of growing up with a parent with dementia. The two researchers differed mostly on those used about other people and their actions, conventional metaphors, and what Lakoff and Johnson ${ }^{31}$ call structural and orienting metaphors.

In the second step, we reflected upon and discussed the chosen metaphors seen in a more general context. This context was knowledge concerning dementia, studies about people with YOD and their children, the broader cultural and societal context for families with a person living with YOD, and services provided to them by the health care system. Among the tools proposed by Steger ${ }^{25}$ in this stage, we especially looked for the functions that the metaphors might have in the informants' presentation of their experiences.

In the third step, we returned to the original interviews to investigate the meaning and implications of the metaphors in each informant's narratives about his or her experiences. Then, we analytically condensed our findings in four themes, and we also identified four core metaphors indicating the themes.

\section{Ethics}

The study followed the ethics outlined in the revised Declaration of Helsinki $\mathrm{i}^{36}$ and those of the Regional Committee for Ethics in Medical Research, Southern Norway. The Norwegian Data Protection Authority also approved the study. The informants received oral and written information about the study and gave written consent before they were interviewed.

\section{Results}

The identified metaphors covered the informants' relations to the disease, to the self, to the parent, and to others. These metaphors reflected the participants' experiences of the development and course of dementia, the emotional reactions to their own situation, the changing relations between the parent and child, and the informants' relations to public health services. From the identified metaphors concerning the themes, we were able to abstract four core metaphors: "my parent is sliding away"; "emotional chaos"; "becoming a parent to my parent"; and "a battle".

\section{The development and course of the dementia:"my parent is sliding away"}

The main meaning of the metaphors about dementia includes stories about a parent gradually losing control, being less recognizable, and becoming stranger. Finally, the parent is lost in his or her world, a place where the child can no longer reach the parent.

The development and course of the dementia disorder of all parents was gradual, from the nearly unnoticeable changes in habits and reactions, to more obvious deviances from normal behavior. The diagnosis eventually places the strange reactions within an understanding of a disease and medical discourse. Still, reactions to the dementia development are experienced and sifted within a cognitive and emotional bonding to the parent with his or her personality and the special version of the parent-child relationship. 
The development and course of the disease is described as sliding slowly.

The metaphors of dementia are rather few, often global, and put in the everyday language of young people. The informants did not usually talk about the disease using specific and precise symptoms of a disease, which they now may have acquired more knowledge about. As one of the informants expressed: "You are in doubt when he is clear and when he is muddle-headed (...). I thought he was muddled, and when he should have driven me to friends, he did not know the way, and was ... confused".

The initial signs of dementia were attributed to distraction, stress, fatigue, or the accentuation of personality traits. The personality of the parent was seen as changed and the parent was described as "flat", lacking initiative. The informants thought at some point that the parent should pull him/ herself together, concentrate, and eventually reduce stress in daily life. The lapses and mistakes became more annoying, the repetition of remarks more irritating, and many children described that they became angry. Also, the parent may have become "more angry and irritated; now it has got the "upper hand", as told by one of the informants.

The diagnosis was told to have come as "a shock"; initial information was not grasped, and the implications were only partly understood. Moreover, the informants pointed at the parent's confusion with metaphors, indicating an increasing lack of control. Some parents were sometimes observed without manners and shame, as the child saw it. One informant expressed: "He gives a damn!" A remedy for this gradual loosening of control was suggested to be "firm frames", restricting the person in more simplified surroundings with few things around.

The core experience of the progression of the dementia was to lose the parent, as one of the informants expressed it: "It is so sad to lose your father in this way. It may go slowly, but at last the person is seen as lost in his own world". Another informant said: "She has, in a way, disappeared from me for a while".

One of the informants described the difference between the person he knew and the figure he sees now, like this: "It was felt as if someone had taken him out of his body and then put him into another, and he still looked the same. And then he was really not that at all". Another informant compared the process with plants growing and decaying: "You sit there and see a human being wither away".

Some sadly described how the parents lost interest in them and their situation. The parent's engagement in his or her child faded away; the parent became more distant and slid into "the fog". One informant described a social and outgo- ing father as one who "has locked himself in". Some saw the disappearance as a more active rejection by the parent; he or she became angry at, and abusive towards the child.

\section{Feelings: emotional chaos}

The main theme for the metaphors with the richest and most varied imagery is found in the narratives about the informants' emotions and reactions about their own situation.

The progress of dementia occupied the informants' thoughts and minds and gave rise to a wealth of emotions. "Thousands of thoughts are coming in", as one said. Another informant compared his head with a centrifugal machine:

In the eight class, I lacked concentration, very much. My head was like a centrifugal machine, repeating that my father had dementia. I will never get him back. This spin occupied my head, destroyed my concentration and my interest in school.

This everyday experience can be described as an uncontrollable and unpredictable emotional tour. "Chaos" is a metaphor used by some of them. One informant expressed: "I had stretched the rubber band too far, as we say. Then I was in in emotional chaos. I began to cry for nothing at all, see? But now I have got more control over my feelings, I think".

Another respondent called the experience "a trauma", and many metaphors indicated strong and rather dramatic reactions. "I think I had broken down".

The children described that they had been "in another world" compared to their age mates and friends; their attention was in another place. One informant said: "I was much quieter in the classroom. I was sitting and thinking, staying in my own world". One described it as "A dark world. But you are then in your own world, you see. Everything around you becomes completely dark. Then all there is, is to stay at home. That was all that mattered". This world away from others parallels the world in which they see their parent disappear.

One informant gave a description of losing his own feeling of being an actor with his own will and emotions; he felt he became a zombie, a robot. A strategy of putting themselves in "a bubble" was also mentioned. Some emotions rise to the surface; they are impossible to push away. One informant used a metaphor about the surface of water: "It happens that the family sometimes gets their heads over the water, breathing. It occurs all the time, so that we have to get our heads over the water, and when we have arrived we needed a break".

They described cognitive ways of distancing themselves from these experiences. One of the informants 
expressed: "I put it in the same sack as all the other remarks that relate to the illness". Also, "escaping" was another metaphor used about cognitive coping strategies and ways of withdrawing.

The emotional strain was heavy; the informants described it as a burden: "Like carrying a stone on my shoulders every day". Relief was like feeling that the stone fell off. The strain of the emotional burden and worries may actively be moved from "focus" (from the forefront of the brain) to the "back of the head" (or moved out of attention) when the person lived in a place away from the parent. One informant expressed: "It is not forgotten, I have it in the back of my head, but I do not think very much on it (the dementia of the parent) any longer. For I have a girlfriend, I have friends, I have a job. So life continues in a way".

The informants said that when they or their parents moved out of the home, it had been a relief in many ways, and physical distance reduced the burden. They indicated that when the parent moved to a nursing home, it was like a relief, but it also evoked other feelings like having a bad conscience and regret. A daughter mentioned that she felt "cold hearted", and had been "a cold person":

It is so hard: The consequence is that I am now left with anxiety, guilt, and unrest. I have so many ups and downs that I feel sick. To move her (mother) out has resulted in anxiety, guilt, and unrest: I have so many journeys up and down during the day that I get tired of it. I can be so happy that my heart will explode, and an hour later I am so sad that I will not live any longer.

Some children experienced that while they felt some control when their parent was at home, they lost control after the parent had moved out. One of the informants expressed: "After she moved to a nursing home, I nearly lost control over everything. I was not able to open letters, to do anything. I completely lost my concentration".

The metaphors about emotions thus indicate that the feelings can be so complicated and contradictory, chaotic and turbulent, that the informants try to push them back or "lock them inside", not to be overwhelmed. One informant mentioned that dementia is "a taboo, no one shall know about it" and "You cover it up". Their extraordinary experiences are difficult to communicate to others.

\section{The transformed relations: becoming}

\section{a parent to my parent}

The core experience of having a parent with YOD is the completely unexpected and unusual transformation of parent-child relations: the child gradually becomes "a parent to my parent". They see their parents becoming less and less able to take care of themselves and their families; they are less responsible and lose their parental roles. The parent becomes more and more childlike, as they see it: "I think it is difficult to see a person you are close to in so many ways ... While you grow up, he becomes younger in some ways, and regresses to becoming like a child in behavior, verbally, and all such things".

The parent, as a foundation of a young adult's own development, is passing away, as one informant said:

I hate the role of being daddy to my daddy. I hate it! It is not my role to be a daddy to my father. I shall be a son! I shall be ... as I said, I shall have time to be young. I can't fly around and be daddy to my daddy. It is completely wrong! It is not a responsibility a 13-year-old boy shall have!

Another informant took on the total responsibility for her mother: "I did everything for her!" The daughter became socially isolated concentrating on the task: "So I had no network, no friends, because I had to prioritize mummy. I do not regret it ... Well, I do not know quite now. But I just had to do it, because there was no one else. And if I had not done it, I would have been left with bad conscience". She summed up the whole situation by saying: "She is my child, she really is". Some of the informants mentioned that they grew up rather quickly and became "very adult" fast.

The youth's own development had to be set aside, as one informant formulated her situation like this:

I had to look after mummy. Mummy came first (laughter). It was not so many other things, any other thing that came first. Not I anyway, not school, not friends, not a boyfriend. Not anything of what I wanted to do. That was always a second priority. (..). You just have to. But everything that was about me, I forgot! I neglected myself.

The children had various experiences and were involved in various ways as the dementia disorder progressed. The most involved children were those who lived together with the parents as the dementia disorder progressed. Reactions may change when seen in retrospect, and this was expressed by one of the informants in this way: "So I do not feel that I missed something, even if I had been home with daddy, even if I might have felt it at that time".

\section{The provision of public services: a battle}

All informants experienced that the provision of public services came late, and that the provided service was 
inappropriate, insufficient, and unsatisfactory. The help the children received came late - if at all. The informants often described the communication with the public health care system as a "battle" or a "fight". The meetings with personnel at the municipal service center were characterized by remarks like "cultural clash", a "blind curtain" was down, they met "a wall", and they were not at the same "wavelength". The health personnel who provided the services did not seem to listen to their stories or understand their situation.

"Hand" was a frequent metaphor. The informants have a personal, nonbureaucratic view of contact with the health care service; they missed someone who could take them by hand and follow-up with them, like a parent or another responsible adult, allowing them to be a child. They wished that their parents were well cared for, and they wanted to be supported by a person who would understand them. They felt left alone, overlooked, out of focus, and did not want to walk alone on their burdensome journey.

\section{Discussion}

By analyzing metaphorical expressions in narratives, we have described how the children of parents with YOD experienced the development and progression of their parents' dementia disorder, as well as identified the needs for support and assistance they have. Metaphorical analysis has unveiled significant themes and ways of handling the challenges, and it presented them to others in the stories of children of parents with YOD. The analysis shows their "relations to the disease", "to the self", "to the parent", and "to others". The findings are discussed in the order that the themes are organized, and they are presented empirically.

As emerging adults, ${ }^{37}$ the informants are now in a period when they can report their present and previous situations, reflect on their experiences of growing up with parents with a dementia disorder, and evaluate the impact that this had on their own development. We find that metaphors are frequently used, especially to describe the informants' emotions. The metaphors give condensed pictures of complex feelings and fundamental experiences. Metaphors are particularly likely to be used in situations in which ordinary language seems inadequate. They can express the ways in which different stressors are perceived. ${ }^{28}$

The experiences related to the disease are described by metaphors signifying the experience that the parents are sliding away. According to the informants, the personalities of the parents have changed, the parents have become more difficult to relate to, or he or she seems to become more unengaged with the child. The child has gradually "lost" his or her parent, both as a person and as his or her parental figure. The children miss an "ordinary" childhood in a normal life course, as they expect and see among their age mates.

Also, people with YOD describe their experiences of dementia as sliding away. ${ }^{38}$ People with dementia report that they experience being present and sliding away at the same time. They think that others may see them as completely "gone" sometimes. In these aspects, the metaphors of the persons with dementia are parallel to those of our informants. But the positions of the narrators and the existential implications are different among the parents with dementia and their children.

Metaphors of emotions are frequently used by the informants, and they often indicate strong feelings. The informants all pity their parents, but they have complicated and contradictory feelings - emotions that are normally forbidden when directed at the patients - such as annoyance, irritation, loss of temper, and aggression. Metaphors are convenient when the children are talking about complicated feelings directed at their ill parents. The informants can simplify and condense the narratives of their feelings with words from another sphere. The metaphors of emotions seem to serve a dual function: they indicate feelings; and at the same time, they keep the emotions at a distance - they "un-emotionalize" them. Thus, the metaphors make it easier for informants to communicate their emotions and reflect upon them.

Some describe that their everyday experiences and thoughts have periodically been totally absorbed by having a parent with a dementia disorder. Our informants have an experience of being "alone in the world", with few or no one to talk to - their experience deviates too much from those of their age mates. Also, persons with YOD describe that they are feeling increasingly isolated with their thoughts, becoming "all alone in the world". 38

The core metaphors of "the relationship to their parent" revolved around becoming "a parent for my parent" and "my parent is my child" - seeing the parent becoming more and more like a child. Describing the parent in a child-like position does not support the dignity of the parent. ${ }^{28}$ While the children have experienced losing their parents, they themselves became more "adult" earlier than expected. They take on parent-like responsibilities for their parents; the roles, responsibilities, and statuses are exchanged. Some informants seem to have accepted these responsibilities without regrets; others emphasize their lack of opportunities for personal development in their youth. 
Our findings show that an analysis of metaphors highlights important existential aspects of becoming a self among children of parents with YOD. The informants feel that they have had reduced possibilities to focus on their own development while they have been immersed in their parents' struggles to preserve a sense of self. The children have a feeling - not of losing themselves, but of not having been able to develop an identity as they would have liked during their youth. ${ }^{17}$ One risk of this situation is that they may lose their sense of being an actor in their own life - a great risk when it comes to developing a robust sense of self.

Children growing up under emotional chaos and adverse circumstances may develop resilience, extraordinary coping resources to handle stress, and barriers in life, ${ }^{39-44}$ which has emphasized that vital for coping well with stressors in life is acquiring a sense of coherence, an experience that events are comprehensible, meaningful, and manageable. To grow up with a parent with a dementia disorder is an unexpected and non-normative youth experience; it is not easy to understand, accept, or handle. Even if the experience of becoming mature and an adult early on might provide coping resources, it is reasonable to expect that some children will beome vulnerable later in life. A consistent finding, and one that is in line with the buffering hypothesis, ${ }^{45}$ is that social support modifies the negative effects of stress on well-being and psychosocial problems. ${ }^{46}$ Support from family is important in youth ${ }^{47}$ for health and development of a sense of self, as are contact with and support from friends. ${ }^{47,48}$ Both of these relationships are greatly disturbed by the dementia of their parent.

The dominant metaphors about the "relationship to others", primarily to the health care services, are battle metaphors, which express that the families fought for help for the parents with dementia. The informants' own situations have been overlooked, as they recount it. This study supports the results from other studies, ${ }^{11,12}$ in that children of persons with YOD feel neglected and are in great need of being seen in their own right.

Our study highlights that service providers should listen to the children's stories to perceive how metaphors convey their experiences and to identify the needs for support they have for their own development. Also, a study of spouses of persons with dementia ${ }^{49}$ underlines that paying attention to metaphors can aid in the understanding and support of well-being. Metaphors can open up the communication of complicated and forbidden feelings. Words like "chaos" or "trauma" point at existential experiences, likely with negative consequences for later life stages among some of our informants. The circumstances of their childhood and personal development were adverse during a vulnerable period of their lives, and some may need professional help to reduce their stress and burden to prevent later psychological problems.

\section{Limitations of the study}

Analyses of metaphors have their limitations. When the purpose of a study is to acquire more detailed information about the experiences of everyday life, the family system, and meetings with the health services professionals, other qualitative methods. ${ }^{35,50}$ may be more suitable. The strength of the analysis of metaphors is that it allows one to open condensed expressions of emotions and experiences, especially those that are difficult to convey with other words.

The findings of our study cannot be generalized in a statistical sense, but we argue that our main findings can be transferrable ${ }^{51}$ to other children of persons with YOD, and perhaps also to younger children. The public health system in Norway is well developed when compared to many other countries. This strengthens the assumption that the informants' experiences of being neglected by the service system are transferable to less developed welfare systems.

Further research should include studies among younger children, as well as studies exploring their use of different targeted services. Longitudinal studies are also warranted, looking at the long-term consequences of the children's experiences and their need for health care services over time.

\section{Conclusion}

The present study revealed that children of parents with YOD are a group with unmet needs for support. A formalized system where the children can get into contact with public service providers in order to receive information about the dementia diagnosis, the prognosis, and available services should be established. The service providers must listen to the children's stories, as well as perceive how the children's metaphors convey their experiences and needs for support they have for their own development. Health and social personnel must give the children tailored support during the progression of the dementia disorder within a framework of family-oriented programs for a chain of coordinated services. Also, meetings with other young people of their own age will be important for peer support and mutual understanding.

\section{Acknowledgments}

First, the authors wish to thank the participants for sharing their experiences. Second, the authors want to thank The Research Council of Norway, who supported the study. 


\section{Disclosure}

The authors report no conflicts of interest in this work.

\section{References}

1. Harvey RJ, Skelton-Robinson M, Rossor MN. The prevalence and causes of dementia in people under the age of 65 years. $J$ Neurol Neurosurg Psychiatry. 2003;74(9):1206-1209.

2. Prince M, Bryce R, Albanese E, Wimo A, Ribeiro W, Ferri CP. The global prevalence of dementia: a systematic review and metaanalysis. Alzheimers Dement. 2013;9(1):63-75. e2.

3. Engedal K, Haugen PK. Demens Fakta og Utfordringer: En Lcerebok [Dementia Facts and Demands]. Tønsberg, Norway: Forlaget Aldring og Helse; 2009. Norwegian.

4. van Vliet D. Young Onset Dementia: Characteristics and Impact [dissertation]. Maastricht, the Netherlands: Department of Psychiatry and Neuropsychology, School for Mental Health and Neuroscience, Maastricht University; 2012.

5. Skovdal K, Palo-Bengtsson L, Anttila S, et al. Yngre Personer med Demenssjukdom och Närstående Till Dessa Personer. En Kunnskapssammansettning [People with Early-Onset Dementia and their Relatives. A Summary of Knowledge]. Institutet for utveckling av metoder i socialt arbete. No 112-1. Stockholm, Sweden: Socialstyrelsen; 2007. Swedish.

6. Svanberg E, Spector A, Stott J. The impact of young onset dementia on the family: a literature review. Int Psychogeriatr. 2011;23(3):356-371.

7. Haugen K. Yngre personer med demens og deres familie: "Hjelpeapparatet er mangelfullt og tar ikke ansvar " [People with early-onset dementia and their relatives: "The healthcare services are inadequate and do not act with responsibility"]. Demens. 2004;8(2):20-23. Norwegian.

8. Haugen PK. En må selv være pådriver: tilbud og mangel på tilbud til yngre personer med demens. In: Krüger ERM, editor. Evige Utfordringer: Helsetjenester og Omsorg for Eldre: Et Festskrift til Knut Engedal på 60-års Dagen [Eternal Challenges: Health Care and Care for the Elderly]. Tønsberg, Norway: Forlaget Aldring og helse; 2006:46-62. Norwegian.

9. Allen J, Oyebode JR, Allen J. Having a father with young onset dementia: the impact on well-being of young people. Dementia. 2009; 8(4):455-480.

10. Kjällman-Alm A, Norbergh KG, Hellzen O. What it means to be an adult child of a person with dementia. Int J Qual Stud Health Well-Being. 2013;8:21676.

11. Barca ML, Thorsen K, Engedal K, Haugen PK, Johannessen A. Nobody asked me how I felt: experiences of adult children of persons with young-onset dementia. Int Psychogeriatr. 2014;26(12):1935-1944.

12. Millenaar JK, van Vliet D, Bakker C, et al. The experiences and needs of children living with a parent with young onset dementia: results from the NeedYD study. Int Psychogeriatr. 2014;26(12):2001-2010.

13. Gelman CR, Greer C. Young children in early-onset Alzheimer's disease families: research gaps and emerging service needs. Am J Alzheimers Dis Other Demen. 2011;26(1):29-35.

14. Borg M. The Nature of Recovery as Lived in Everyday Life: Perspectives of Individuals Recovering from Severe Mental Health Problems [dissertation]. No 110. Trondheim, Norway: University of Science and Technology; 2007.

15. Johannessen A. Dementia and Public Health: With Focus on Access to Society [dissertation]. No 6. Gothenburg, Sweden: Nordic School of Public Health NHV; 2012.

16. Erikson EH. Identity and the Life Cycle. Psychological Issues. Monograph 1. New York, NY: International University Press; 1959.

17. Erikson EH. Identity: Youth and Crisis. New York, NY: WW Norton; 1968.

18. Kohut H. The Analysis of the Self. New York, NY: International Universities Press; 1971.

19. Kohut H. The Restoration of the Self. New York, NY: International Universities Press; 1977.
20. Kohut H. On the continuity of the self and cultural self objects. In: Strozier DC, editor. Self Psychology and the Humanities: Reflections on a New Psychoanlaytic Approach. New York, NY: Norton; 1985:232-243.

21. Stratton P. Contemporary families as contexts for developments. In: Valsiner J, Connolly KJ, editors. Handbook of Developmental Psychology. London, UK: Sage Publications Ltd; 2003:333-357.

22. Kinderman T. Children's relationships and development of personcontext relations. In: Valsiner J, Connolly KJ, editors. Handbook of Developmental Psychology. London, UK: Sage Publications Ltd; 2003:407-430.

23. Ricoeur P, Czerny R. The Rule of Metaphor: The Creation of Meaning in Language. London, UK: Routledge and Kegan Paul; 2003.

24. Spiggle S. Analysis and interpretation of qualitative data in consumer research. J Consum Res. 1994;21(3):491-503.

25. Steger T. The stories metaphors tell: metaphors as a tool to decipher tacit aspects in narratives. Field Methods. 2007;19(1):3-23.

26. Sontag S. Illness as Metaphor. New York, NY: Farrar, Strauss and Giroux; 1978.

27. Montagne M. The metaphorical nature of drugs and drug taking. Soc Sci Med. 1988;26(4):417-424.

28. Johannessen A, Möller A, Haugen PK, Biong S. A shifting sense of being: a secondary analysis and comparison of two qualitative studies on youngonset dementia. Int J Qual Stud Health Well-Being. 2014;9:24756.

29. Lindseth A, Norberg A. A phenomenological hermeneutical method for researching lived experience. Scand J Caring Sci. 2004;18(2): 145-153.

30. Mishler EG. Research Interviewing: Context and Narrative. Cambridge, MA: Harvard University Press; 1986.

31. Lakoff G, Johnson M. Metaphors We Live By. London, UK: University of Chicago Press; 2003.

32. Sacks S, editor. On Metaphor. Chicago, IL: University of Chicago Press; 1979.

33. Kvale S. The qualitative research interview: a phenomenological and a hermeneutical mode of understanding. Journal of Phenomenological Psychology. 1983;14(2):171-196.

34. Kvale S. To validate is to question. In: Kvale S, editor. Issues of Validity in Qualitative Research. Lund, Sweden: Studentlitteratur; 1989:73-92.

35. Denzin NK, Lincoln YS. The SAGE Handbook of Qualitative Research. London, UK: Sage; 2005.

36. World Medical Association [webpage on the Internet]. WMA Declaration of Helsinki - ethical principles for medical research involving human subjects. Ferney-Voltaire, France: World Medical Association; 2013. Available from: http://www.wma.net/en/30publications/10policies/b3/ index.html. Accessed December 4, 2014.

37. Arnett JJ. Emerging Adulthood. Oxford, UK: Oxford University Press; 2004.

38. Johannessen A, Möller A. Experiences of persons with early-onset dementia in everyday life: a qualitative study. Dementia (London). 2013;12(4):410-424.

39. Shih M. Positive stigma: examining resilience and empowerment in overcoming stigma. Annals of the Academy of Political and Social Science. 2004;591(1):175-185.

40. Bonanno GA. Uses and abuses of the resilience construct: loss, trauma, and health-related adversities. Soc Sci Med. 2012;74(5):753-756.

41. Schanke AK, Thorsen K. A life-course perspective on stigma-handling: resilience in persons of restricted growth narrated in life histories. Disabil Rehabil. 2014;36(17):1464-1473.

42. Antonovsky A. The sense of coherence as a determinant of health. In: Matarazzo JD, Weiss SM, Herd JA, Miller NE, Weiss SM, editors. Behavioral Health: A Handbook of Health Enhancement and Disease Prevention. New York, NY: Wiley; 1984:114-129.

43. Antonovsky A. Health, Stress, and Coping: New Perspectives on Mental and Physical Well-Being. San Francisco, CA: Jossey-Bass Publishers; 1985.

44. Antonovsky A. Unraveling the Mystery of Health: How People Manage Stress and Stay Well. San Francisco, CA: Jossey-Bass Publishers; 1987. 
45. Cohen S, Wills TA. Stress, social support, and the buffering hypothesis. Psychol Bull. 1985;98(2):310-357.

46. Cohen S, Gottlieb BJ, Underwood LG. Social relationships and health. In: Cohen S, Underwood L, Gottlieb B, editors. Social Support Measurement and Interventions: A Guide for Health and Social Scientists. New York, NY: Oxford University Press; 2000:3-25.

47. Segrin C. Age moderates the relationship between social support and psychosocial problems. Human Communication Research. 2003;29(3): 317-342.

48. Parker RG, Parrott R. Patterns of self-disclosure across social support networks: elderly, middle-aged, and young adults. Int $J$ Aging Hum Dev. 1995;41(4):281-297.
49. Golden MA, Whaley BB, Stone AM. "The system is beginning to shut down": utilizing caregivers' metaphors for dementia, persons with dementia, and caregiving. Appl Nurs Res. 2012;25(3):146-151.

50. Wertz FJ, Charmaz K, McMullen LM, Josselson R, Anderson R, McSpadden E. Five Ways of Doing Qualitative Analysis: Phenomenological Psychology, Grounded Theory, Discourse Analysis, Narrative Research, and Intuitive Inquiry. London, UK: The Guilford Press; 2011.

51. Malterud K. Qualitative research: standards, challenges, and guidelines. Lancet. 2001;358 (9280):483-488.

\section{Publish your work in this journal}

The Journal of Multidisciplinary Healthcare is an international, peerreviewed open-access journal that aims to represent and publish research in healthcare areas delivered by practitioners of different disciplines. This includes studies and reviews conducted by multidisciplinary teams as well as research which evaluates the results or conduct of such teams or healthcare processes in general. The journal covers a wide range of areas and welcomes submissions from practitioners at all levels, from all over the world. The manuscript management system is completely online and includes a very quick and fair peer-review system. Visit http://www.dovepress.com/testimonials.php to read real quotes from published authors.

Submit your manuscript here: http://www.dovepress.com/journal-of-multidisciplinary-healthcare-journal 